\title{
El giro documental en algunas producciones literarias y cinematográficas de hijos de desaparecidos en Argentina
}

The documentary turn in some of the film and literary production by the children of the missing people in Argentina

A viragem documentária em algumas produções literárias e cinematográficas de filhos de desaparecidos na Argentina

\section{Lara Segade}

UNIVERSIDAD DE BUENOS AIRES, ARGENTINA

Doctora en Letras (UBA) y profesora de Literatura Argentina I en la Universidad de Buenos Aires. Ha publicado en forma digital El lugar de la guerra. Relatos de Malvinas en la cultura argentina (1982-2012) (CLACSO, 2016); y los capítulos "Contar la guerra, explicarse la derrota. Entrecruzamientos entre ficción y testimonio en los primeros relatos sobre Malvinas", en María Guadalupe Silva (coord.), Literatura y representación en América latina. Diez ensayos críticos (NJ Editor, 2012) y "Capítulo 5. Representaciones", en Pensar Malvinas (Ministerio de Educación, 2009), en colaboración con Pablo Luzuriaga; además de artículos en revistas nacionales e internacionales. Correo electrónico: larasegade@gmail.com

\footnotetext{
Artículo de investigación

Este texto forma parte de un proyecto de investigación en torno a las relaciones entre cine y literatura en el marco de las representaciones culturales del pasado reciente argentino.

Documento accesible en línea desde la siguiente dirección: http://revistas.javeriana.edu.co 


\section{Resumen}

En los últimos años, es posible detectar que, en la literatura argentina, un giro documental ha venido a completar, ya que no a sustituir, el giro subjetivo al que una década atrás se refirió, entre otros autores, Beatriz Sarlo. En el cine argentino, algunos de los rasgos de este giro aparecen antes en relación con lo que $\mathrm{Hal}$ Foster llamó "retorno de lo real". Este trabajo busca reflexionar en torno a las transformaciones que, en este sentido, tienen lugar tanto en la literatura como en el cine contemporáneos, a partir del análisis de una serie de libros y películas producidos por hijos de personas desaparecidas durante la última dictadura militar.

Palabras clave: literatura argentina; cine argentino; hijos de desaparecidos; giro documental; lo real

\section{Abstract}

In recent years, it has been possible to detect in Argentine literature, that a documentary turn has come to complete, and not to replace, the subjective turn to which a decade ago Beatriz Sarlo and others referred to. Some aspects of this "turn" in Argentine cinema, appeared earlier in relation to what $\mathrm{Hal}$ Foster called "the return of the real". This work seeks to reflect on the transformations that, in this sense, take place in both literature and contemporary cinema, based on the analysis of a series of books and films produced by the children of the people who disappeared during the last military dictatorship.

Keywords: Argentine literature; Argentine cinema; children of the disappeared; documentary turn; the real

\section{Resumo}

Nos últimos anos é possível detectar que, na literatura argentina, uma viragem documentária tem completado, porém não substituído, a viragem subjetiva a que uma década atrás se referiu, entre outros, Beatriz Sarlo. No cinema argentino, algumas das características desta viragem aparecem mais cedo em relação com o que Hal Foster chamou de "retorno do real". Este trabalho visa refletir em torno das transformações que, neste sentido, ocorrem tanto na literatura quanto no cinema contemporâneos, a partir da análise de uma série de livros e filmes produzidos por filhos de pessoas desaparecidas durante a última ditadura militar.

Palavras-chave: literatura argentina; cinema argentino; filhos de desaparecidos; viragem documental; o real 
En La casa de los conejos (2008), Laura Alcoba relata algunos de los episodios que vivió a sus siete años, cuando sus padres, militantes montoneros, pasaron a la clandestinidad. La rememoración es difícil, porque las percepciones de la niña son parciales, porque la propia clandestinidad escamotea los datos y porque, finalmente, como dice Borges en "El Aleph", con el paso del tiempo el olvido ha hecho su trabajo. Por otra parte, las palabras que se usaban entonces a su alrededor estaban destinadas a la distracción y al engaño: de modo que el lenguaje es el primer objeto de revisión de esta novela, que tiende a desandar el camino de un relato, pero que al mismo tiempo avanza en la construcción de uno nuevo, propio, para lo cual el gesto fundamental es el de la configuración de una voz narrativa que conjuga la percepción de la niña y la comprensión de la adulta.

Con su padre preso, Laura Alcoba y su madre se van a vivir, junto con Cacho y Diana, una pareja de militantes, a una casa en la que un criadero de conejos funciona como pantalla para una imprenta clandestina. A pesar de que a lo largo de la novela solo hay nombres de pila o apodos, cuando cerca del final se hace referencia a la hija de Cacho y Diana, de la que no se supo nada después del ataque a la casa de los conejos, se dicen su nombre y su fecha de nacimiento: es Clara Anahí Mariani, nacida el 12 de agosto de $1976 .{ }^{1} \mathrm{El}$ nombre, no solo real sino por todos conocido, irrumpe en la ficción, casi se incrusta en ella al modo de un ancla en la realidad e incluso en lo real, en el sentido lacaniano del término, que la crítica contemporánea ha retomado para pensar precisamente este tipo de irrupciones, en el arte, de algo del orden de lo traumático que resiste a la simbolización. En efecto, con el nombre de Clara Anahí ingresa a la novela uno de los aspectos más dramáticos y de más difícil simbolización de la última dictadura militar: el robo de bebés, su apropiación por familias sustitutas generalmente de los militares o ligadas a ellos, la sustitución de sus identidades, su desaparición.

El gesto de Alcoba puede leerse en el marco de lo que, en los últimos años, parte de la crítica entendió como un giro documental de la literatura argentina que ha venido a completar, ya que no ha sustituir, el giro subjetivo al que una década atrás se refirió, entre otros, Beatriz Sarlo (2005).

1 Clara Anahí Mariani es la nieta de Chicha Mariani, una de las fundadoras de Abuelas de Plaza de Mayo. La búsqueda incansable de Clara Anahí, apropiada tras el asesinato de sus padres, se ha convertido en un emblema de la lucha de las Abuelas. 
El registro etnográfico de los lenguajes, la revalorización de la figura de autor, las "incrustaciones" en el texto, casi sin mediación, de elementos de lo real o materiales textuales "cortados y pegados" (fragmentos de mails, de diarios), la preeminencia de un vínculo de tipo indicial o metonímico con lo real por sobre lo metafórico o alegórico son algunos de los rasgos de este "giro documental" que, para Sandra Contreras (2013), constituye una de las formas más interesantes del retorno del realismo durante los últimos años. Parte de la crítica ha destacado el interés que, en este nuevo contexto, muestra la literatura hacia aquellos otros discursos que hasta ahora habían mantenido -o, al menos, pretendido mantener- un vínculo más directo con lo real, como el testimonio o la etnografía (Sarlo "Sujetos y tecnologías"). ${ }^{2}$

En este trabajo, quisiera en primer lugar preguntarme por el modo en que el documentalismo se articula en una serie de producciones, no solo literarias sino también cinematográficas realizadas por hijos de desaparecidos durante la primera década del siglo XXI. Entre las primeras, se destacan especialmente Los topos y 76, de Félix Bruzzone, La casa de los conejos, de Laura Alcoba, y Diario de una princesa montonera, de Mariana Eva Pérez. ${ }^{3}$ En el ámbito cinematográfico, también surgen unos años antes, una serie de filmes dirigidos por HIJOS. Tras el puntapié inicial de Historias cotidianas de Andrés Habegger en 2001, llegó la muy disruptiva Los rubios, de Albertina Carri en 2003, y luego se sucedieron Papá Iván,

2 Para Beatriz Sarlo (2007), desde los años noventa lo que tiene lugar es un giro etnográfico, según el cual la pregunta, con forma de enigma, por el pasado, es desplazada por un creciente interés en el presente y sus lenguajes, que adopta el modo del registro documental más que el de la representación. Es decir, que tiende a ser incorporado de formas menos mediadas, menos "trabajadas", menos, podría decirse, metaforizadas. Es el caso de algunas de las novelas de Romina Paula, Washington Cucurto o Daniel Link.

3 El Diario de una princesa montonera, publicado en forma de libro en 2012 a partir de la edición de las entradas en un blog desde 2009, es levemente distinto a los otros dos. Sin embargo, la insistencia del texto a un tiempo en su carácter ficcional y verídico permite pensar en tensiones similares a las que aparecen en novelas como Los topos o La casa de los conejos. En ese sentido, puede destacarse el hecho de que Mariana Eva Pérez distorsiona o elide los nombres de los protagonistas de su historia, incluso el de sus padres. Pero en un momento dado se relata el episodio de la colocación de una baldosa recordatoria en el barrio de Palermo, sobre la calle Gurruchaga. En tanto es posible aproximarse allí y leer el nombre completo de los padres de la autora, frente al edificio en el que los secuestraron, la baldosa funciona de algún modo como el nombre de Clara Anahí Mariani en La casa de los conejos: como una incrustación de lo real en la ficción. 
de María Inés Roqué (2004), Encontrando a Víctor de Natalia Bruschtein (2004) y $M$ de Nicolás Prividera (2007), entre las más importantes.

La selección del corpus no es azarosa: los HIJOS ocupan una posición muy singular, la de aquellos cuyas vidas se han visto íntima e irreversiblemente afectadas por la militancia y la desaparición de sus padres, algo que pese a todo no vivieron. En ese sentido, se proponen contar una historia de la que a la vez son y no son partícipes. A esa posición liminar, entre la experiencia y la ficción -como modalidades narrativas, en este caso, respectivamente de la presencia y la ausencia-, se agrega el hecho de que estos HIJOS también son escritores y cineastas, y que además fue con estas obras que dieron inicio a sus carreras. ${ }^{4}$ Así, la conjunción entre un dato empírico-biográfico de fuerte pregnancia en la obra y el trabajo, específicamente cinematográfico o literario, sobre esos materiales biográficos hace de estos artistas y de sus producciones un espacio privilegiado para pensar en las nuevas formas en que la ficción argentina entra en contacto con la realidad y en cómo, en ese contacto, irrumpe algo del orden de lo real, en el sentido psicoanalítico del término.

II

En su artículo "Tierra de la memoria", del año 2010, Carlos Gamerro traza una periodización posible para la literatura argentina de la dictadura en la que distingue cuatro etapas: la primera es la literatura producida durante la dictadura, en el contexto de persecución y censura. Novelas como Nadie nada nunca o Respiración artificial, ambas de 1980, abundan por tanto en referencias indirectas, desplazamientos, metáforas, alegorías y elipsis. La etapa siguiente, en cambio, está marcada por los testimonios de los participantes directos, destinados a sacar a la luz lo que había sido ocultado durante los "años oscuros". El texto fundamental es el Nunca más, aunque también en las novelas es predominante el rasgo testimonial,

4 En efecto, después de 76 y Los topos, Félix Bruzzone publicó las novelas Barrefondo y Las chanchas, además de cuentos en numerosas antologías y revistas. Laura Alcoba, por su parte, publicó Los pasajeros del Anna C., Jardín blanco, El azul de las abejas y La danse de l'araignée, que todavía no ha sido traducido al español. Mariana Eva Pérez siguió llevando adelante su blog, cuyas entradas entre 2009 y 2012 constituyen el libro Diario de una princesa montonera. En cuanto al cine, en muchos de estos casos también las películas sobre la desaparición de los padres son el primer paso de una carrera que luego seguirá por otros rumbos. Por citar solo el caso más conocido, Albertina Carri dirigió los largometrajes Géminis (2005), La rabia (2008) y Cuatreros (2016). 
como sucede en Recuerdo de la muerte, de Miguel Bonasso. Ahora bien: la distinción entre el tercer y cuarto período parece volverse más difusa. En el tercero aparece la literatura de los testigos -en el sentido de "observadores" y no de participantes-:

niños o como mucho adolescentes cuando aquel fatídico 24 de marzo de 1976, demasiado jóvenes para la militancia y mucho más para la guerrilla; testigos a veces directos, como Laura Alcoba en La casa de los conejos $[\ldots]$ a veces meramente testigos de los silencios, las verdades a medias, o directamente las mentiras que nuestros mayores nos impartían. En esta etapa regresa la mirada indirecta, los testimonios sesgados y refractados de la primera, pero ahora no por necesidad práctica sino por elección estética, como la más adecuada a la naturaleza incompleta, bloqueada, turbia de la experiencia. (Gamerro)

La última etapa, finalmente, es la de quienes "no tienen recuerdo personal alguno; que saben porque escucharon las historias familiares, o leyeron, o investigaron, o imaginaron lo sucedido" (Gamerro). Como ejemplo, Gamerro propone precisamente a Félix Bruzzone.

Es cierto que, desde mediados de los años noventa, se produce un resurgimiento de lo testimonial, que al mismo tiempo se ve modificado por el hecho de que, en gran medida, quienes dan testimonio no son ya los participantes directos sino sus hijos, que ocupan una posición liminar respecto de la historia que relatan, en tanto es y no es la suya. En 1997, Juan Gelman y Mara la Madrid editan Ni el flaco perdón de dios, un libro donde por primera vez quienes prestan testimonio son los hijos de desaparecidos. Fuera de eso, sin embargo, el libro es muy parecido a cualquier otra recopilación de testimonios: supone un trabajo de investigación, de grabación y luego de edición por parte de Gelman y La Madrid que pertenecen, en última instancia, a la generación de los padres. Es decir que la voz de los hijos, aunque efectivamente aparece, lo hace todavía bajo la tutela $y$, sobre todo, las formas, de los mayores. En cambio, las nuevas narrativas a cargo de los HIJOS introducen una modificación fundamental en los relatos de la dictadura, según la cual, lo testimonial es impensable fuera de su articulación con lo literario, que es muchas veces una articulación de tipo documental. A partir de allí, entonces, resultaría insuficiente o inútil la distinción entre lo que para Gamerro constituye una tercera y cuarta etapa, es decir, entre lo que Alcoba puede recordar y por tanto documentar y lo que Bruzzone solo puede imaginar y que queda, por lo 
tanto, del lado de la ficción. Más bien quisiera postular que esa forma peculiar que adopta el documentalismo en las producciones de los hijos de desaparecidos tiene más que ver con la contigüidad y la mezcla que con la separación y que supone, por tanto, diversas formas de la liminaridad, en estrecha relación con la posición de testigos liminares, entre partícipes y observadores, que ocupan sus propios autores.

Algo similar puede postularse para el ámbito cinematográfico. En efecto, así como resulta insuficiente, si no forzado, ubicar los textos de Félix Bruzzone y también el blog de Mariana Eva Pérez en la línea de otras producciones testimoniales anteriores, incluso de aquellas en las que participaron hijos de desaparecidos como $\mathcal{N i}$ el flaco perdón de dios; de la misma manera resulta por lo menos insuficiente pensar en estos documentales en relación con otros documentales anteriores sobre la dictadura, de fuerte impronta testimonial, como Cazadores de utopías, de David Blaustein (1996) o Montoneros, una historia de Andrés di Tella (1995) que, pese a que anticipan ya la perspectiva compleja respecto de los setenta y en especial de la militancia que caracterizará a los documentales de los HIJOS, lo hacen todavía "con el lenguaje más estructurado de la política como institución" (Amado 164). Más bien, el surgimiento de estos documentales dirigidos por HIJOS se inscribe en el marco de lo que se conoció como Nuevo Cine Argentino, que se caracterizó, entre otras cosas, por enfatizar el carácter eminentemente indicial de la imagen cinematográfica y por proponer, concomitantemente, un resurgimiento de lo documental no solo en tanto género sino sobre todo en tanto elemento que permea incluso la ficción. En ese sentido, se trata de un cine que también supone diversas formas de contigüidad y de cruce entre lo testimonial y lo ficcional. El hecho de que Nicolás Prividera, director de $M$, no recuerde nada de su madre, desaparecida cuando él tenía seis años, puede leerse como una impugnación a la idea de separación entre quienes recuerdan y quienes solo pueden reconstruir o imaginar. Es posible postular, entonces, que las producciones literarias de los hijos de desaparecidos se ligan con el cine en la medida en que utilizan procedimientos que les son propios, tales como la indicialidad y el registro documental; en especial, con aquellas películas que, en el marco de la renovación del Nuevo Cine Argentino, también apelaron a esos procedimientos y los desarrollaron.

Desde finales de la década del noventa, en el ámbito cinematográfico argentino se producen una serie de transformaciones tanto en el área de la producción, como en la de producción artística y en la propuesta estética. 
El resultado es un "nuevo régimen creativo" (Aguilar 14) que manifiesta su oposición al cine anterior, en especial al de los años ochenta. El llamado Nuevo Cine Argentino supone un retorno del cine documental, pero también "una presencia de lo documental en varias de las películas de ficción" (Aguilar 36). En tanto esta presencia es una forma de relación del filme con lo real, remite a la cuestión del realismo. Sin embargo, como explica bien Aguilar, es necesario puntualizar que el realismo cinematográfico es distinto al de otras manifestaciones artísticas, como la literatura, a partir de las cuales tendió a ser conceptualizado como un código. La distinción remite al carácter indicial y no icónico de la imagen fílmica, es decir, al hecho de que se trata de un "signo que, a diferencia del símbolo (con el que trabajarían la literatura o la pintura), produce la cosa que representa de manera inmediata y captura una secuencia de tiempo que queda registrada en un fragmento de celuloide o en otro soporte material" (Andermann y Fernández Bravo 14).

Es decir que hay, siempre, una naturaleza documental de la imagen que cierto cine -por ejemplo, gran parte del cine argentino de los años ochenta- dejó en segundo plano, al priorizar la reproducción de los códigos del realismo de otras artes, fundamentalmente el teatro. Así, este cine, afirma Aguilar, creyó estar representando lo real, pero estaba representando sus códigos y, por lo tanto, era más costumbrista que realista.

A estas formas se oponen otras que, basadas en la concepción indicial de la imagen fílmica, recuperan una idea de realismo ya no como código sino como una forma de registro. Sin embargo, y esto es lo fundamental, tal noción de realismo no está reñida con la idea de la puesta en escena, es decir, con la idea de un procedimiento, de un artificio.

Por otra parte, si el Nuevo Cine Argentino, surgido en los albores de la crisis del modelo neoliberal y de sus relatos, que eclosionaría en 2001, rompe con lo que había sido el cine de los años ochenta, lo hace en especial con la presentación de argumentos que proveyeran respuestas en relación con lo político y lo identitario. El rechazo de los argumentos en forma de respuestas y del concomitante imperativo de la politización es ante todo el rechazo de las narraciones alegóricas, que se constituye en un rasgo característico del nuevo cine. Estas películas, por el contrario, "perseveran en lo literal": "trabajan con la indeterminación y abren el juego a la interpretación" (Aguilar 24). Son filmes que tienden a evitar el cierre "consolatorio", que mantienen en cambio cierta ambigüedad o apertura. 
III

En efecto, tanto las películas como las narrativas de HIJOS que aparecen durante la primera década del siglo XXI se constituyen muy fuertemente, desde los principios constructivos que les son propios, en la lógica de lo abierto, de lo que no termina nunca de cerrarse. Una de las formas en que dicha lógica se articula es la del desvío: aunque suele haber búsquedas, estas casi nunca siguen un orden, algunas veces ni siquiera tienen un objetivo claro. Aun cuando se intenta ser minucioso y ordenado, tampoco los resultados son los que se esperan. Y si se encuentra algo, en general ocurre por azar. Así, lo que se relata son investigaciones erráticas, inmotivadas, infructuosas.

En el cine, tal vez sea Los rubios donde esta lógica se percibe más claramente: no hay un objetivo claro que guíe la investigación, algo a lo que de antemano se quiera llegar. Asimismo, como ha sido muchas veces destacado, a los testimonios y demás informaciones recogidos no se les da después demasiada importancia. Se les da la espalda, se leen otras cosas encima. En $M$, la búsqueda es más tradicional, pero no por eso más exitosa: Nicolás Prividera busca información concreta sobre la desaparición de su madre y compara la tarea con el armado de un puzzle, del que sin embargo faltan la mayoría de las piezas. En efecto, acceder a cualquier dato resulta imposible: no hay archivos, los entrevistados no saben, no se acuerdan o no quieren hablar. La imposibilidad de conseguir información irá generando más y más desesperación, y hasta momentos de furia. Hay una escena en que esto se vuelve angustiosamente explícito: Nicolás Prividera llama a una compañera de la madre, de la que consigue el teléfono. Enseguida, después de atenderlo y manifestarle su alegría por volver a saber de él, la mujer se excusa diciendo que está atravesando una quimioterapia y que, ante el riesgo de una depresión por la baja de defensas, el médico le prohibió hablar del pasado.

La escena parece la versión cinematográfica de una del cuento "El orden de todas las cosas", de Félix Bruzzone, en donde el protagonista, Primo, emprende una búsqueda a raíz de que aparece, como por arte de magia, una agenda. La búsqueda, que terminará cuando la agenda desaparezca, no parece guiada por una ambición de saber ni de cerrar la historia. La trama avanza como por azar, obedeciendo incluso por momentos a un móvil casi sobrenatural, que son las percepciones de una tía que habla con los animales. Es una trama que avanza sin que se sepa cómo. Y así como no hay guía, no hay memoria completa. Y es en ese contexto que Primo 
llama a una mujer que vive en Bahía Blanca y que parece saber algo de su madre: al hacerlo, descubre, o recuerda que ya había tenido ese número antes, que había llamado y que había hablado con la mujer; incluso había viajado a Bahía Blanca. Pero no consigue recordar qué hablaron en aquel momento. Y eso que se perdió ahora es irrecuperable: la mujer está enferma, no se puede hablar con ella.

El cuento "Otras fotos de mamá" también constituye una narración abierta, llena de desvíos, a cargo de un narrador distraído u olvidadizo. Aunque la historia comienza con una búsqueda intencionada -el acercamiento del protagonista a Roberto, un exnovio de su madre desaparecida, quien le promete buscar unas fotos-, a partir de allí todo comienza a deshilacharse. El narrador se relaciona con Cecilia, la actual pareja de Roberto. En un momento parece que está por producirse una escena amorosa entre los dos, pero al final no pasa nada y el narrador se olvida de pedirle que le recuerde a Roberto lo de las fotos. Tampoco tiene lugar ninguna revelación por parte de Cecilia -que Roberto sea su padre o que haya tenido algo que ver con la muerte de su madre-. La expectativa de que suceda algo importante, algo que permita, de algún modo, cerrar la historia, se frustra una y otra vez. Cecilia comenta lo rico que está el café.

En Una intimidad inofensiva, Tamara Kamenszain (2016) aborda en términos de desvío la investigación que emprende Bruzzone en la conferencia performática Campo de Mayo, estrenada en 2013 como parte del ciclo "Mis documentos" de Lola Arias. La investigación gira en torno a Campo de Mayo, un territorio militar de la provincia de Buenos Aires, en cuyas inmediaciones, de casualidad, vive el propio Bruzzone. En el predio, hoy destinado a usos muy disímiles, funcionó durante la dictadura un centro de detención clandestina en el que, se entera también de casualidad Bruzzone, estuvo detenida y fue asesinada su mamá.

Para Kamenszain, hay una suerte de contigüidad entre el yo y el territorio, una mutua afección que es una mutua definición: en la medida en que se recorre un territorio se define una identidad. Sin embargo, no se trata nunca de definiciones cerradas. En tanto esta investigación no es de tipo detectivesco, no está direccionada -se trata de un investigador distraído, que no sabe bien qué busca ni con qué criterio elige a sus informantes-, en tanto no se busca una verdad predeterminada y, por supuesto, tampoco se llega a ella, en la deriva territorial y narrativa se produce también una deriva identitaria. En el recorrido va apareciendo un yo cada vez diferente: Bruzzone será investigador, piletero, editor y, por último, escritor. 
En efecto, sobre el final, la obra da un giro: aparece un actor que hace de un corredor que entra a Campo de Mayo para entrenarse. Bruzzone, ahora escritor, comienza a trazar derivas posibles de ese personaje en tercera persona. El corredor se mete en Campo de Mayo para ejercitarse -"por deporte", dice Kamenszain- y no para buscar información del cautiverio de la madre desaparecida. Hace otro uso de ese territorio, que es simultáneo al uso que hace el escritor, para escribir su novela, cuyos finales posibles va desplegando Bruzzone a la manera de un "Elige tu propia aventura".

Este permanente desvío que redunda en un nunca llegar puede leerse como un abandono de la trama -la trama de la investigación, de la búsqueda; la trama de simbolización o de puesta en relato; la trama del orden; la trama, en definitiva, de la historia-, en el sentido propuesto por Beatriz Sarlo ("Sujetos y tecnologías") para la literatura de César Aira. En efecto, la relación con Aira es muy evidente en Los topos, donde el narrador, que es un hijo de desaparecidos, emprende la búsqueda de su hermano, supuestamente nacido en la ESMA. Termina sospechando que Maira, una travesti con quien intima, es ese hermano y lo sigue hacia Bariloche; allí la trama comienza a abrirse, a proliferar, a deshilacharse. Si bien, para Sarlo, Aira es un precursor de las novelas de tipo etnográfico, puesto que tiene una mirada documental, en el sentido de que escribe sobre el presente, del que toma sus materiales, también realiza sobre esos materiales operaciones desrealizadoras, "literaturizantes". Una de esas operaciones es el abandono de la trama, que hacia el final de sus novelas se deshace, se abandona, desmintiendo toda etnografía. No hay, dice Sarlo, impugnación más severa de la ilusión representativa que el abandono de la trama en el desenlace: esto es, una impugnación de la historia interpretable, del orden de los hechos, de la continuidad del personaje.

De un modo semejante, en los textos de Bruzzone, el abandono del camino de la reconstrucción de la historia se realiza por medio de operaciones de ficcionalización que, sin embargo, son al mismo tiempo el medio por el cual es introducido el elemento biográfico. En efecto, en la literatura de Bruzzone lo autobiográfico es un elemento central -la desaparición de los padres, la infancia junto a la abuela, su relación ambigua con las organizaciones de Derechos Humanos, en especial HIJOS, su trabajo como piletero, etc.-. Pero estos elementos biográficos entran como por azar, a medida que el narrador se los va encontrando en su camino, o bien, a medida que el narrador olvida su búsqueda reconstructiva, se distrae de ella y la revelación esperada no se produce: es decir, según la célebre formulación de Borges, en 
la medida en que aparece el hecho estético. ${ }^{5}$ En ese sentido, el desvío puede verse como un ir y venir por la frontera entre lo testimonial y lo literario que produce en Campo de Mayo, pero también en los textos y las películas de hijos de desaparecidos hay diversas oscilaciones: entre la biografía y la ficción, entre la primera y la tercera persona, entre lo que se recuerda y lo que se construye o se imagina, o entre lo íntimo y lo público. ${ }^{6}$

IV

En su análisis de Campo de Mayo, Tamara Kamenszain hace especial hincapié en esta última oscilación, que percibe como un movimiento de puesta afuera de lo íntimo: un ejemplo de "intimidad éxtima". Según Jacques Lacan, la extimidad representa a lo más próximo que, al mismo tiempo, hace su aparición en el exterior. Formulación paradojal del modo de ser del sujeto: lo más íntimo habita afuera, como un cuerpo extraño, y produce una fractura constitutiva de la intimidad difícil de aceptar para el sujeto, en tanto que se trata de un real que habita en lo simbólico.

Entonces, la puesta afuera de lo íntimo, movimiento específico que las producciones de los HIJOS realizan en la frontera entre lo testimonial y lo literario, supone una irrupción de lo real en lo simbólico y puede pensarse por lo tanto como una forma de lo que Hal Foster denominó realismo traumático. En su análisis del arte norteamericano de los sesenta y de los setenta, Foster busca separarse tanto de quienes interpretan ese arte como simulacral y, por tanto, superficial e impasible, como de quienes lo interpretan como un arte referencial y, por tanto, comprometido e incluso crítico. Foster parte del análisis de la serie "Muerte en América", de Andy

"La música, los estados de la felicidad, la mitología, las caras trabajadas por el tiempo, ciertos crepúsculos y ciertos lugares, quieren decirnos algo, o algo dijeron que no hubiéramos debido perder, o están por decir algo; esta inminencia de una revelación, que no se produce, es, quizá, el hecho estético" (Borges).

6 Los propios autores se han referido muchas veces a sus propios trabajos en estos términos. En una entrevista realizada al poco tiempo del estreno de Los rubios, María Moreno cuestiona la oposición entre ficción y documento, a lo que Albertina Carri responde: "Por eso al principio uno de los posibles títulos de la película fue Documental 1. Notas para una ficción sobre la ausencia. Con elementos autobiográficos. Y cuando tengo que definirla digo que es una película sobre la ficción de la memoria y no sobre mi vida o mis padres" (Carri y Moreno). Mariana Eva Pérez, por su parte, subtitula su diario "110\% Verdad". Ese leve exceso sobre la verdad es constantemente ironizado a lo largo del libro y toma la forma de, entre otras cosas, la ilustración de muñequitos o corazones sobre las fotos de los padres. 
Warhol, para afirmar que se trata de imágenes a la vez referenciales y simulacrales y proponer una tercera vía de lectura del arte pop, la del realismo traumático. Para Foster lo que se produce allí, entonces, es un encuentro con lo real, que siempre es un encuentro fallido, en la medida en que lo real es lo que queda afuera, lo que no se puede conocer, conceptualizar, poner en palabras: aquello no se puede encontrar sin que se produzca un trauma.

En las reflexiones de Foster se destacan algunos rasgos de lo real, tal como irrumpe en el arte contemporáneo: por un lado, se trata de un real horroroso, siniestro, y que además aparece azarosamente, como el punctum en la fotografía según la conocida formulación barthesiana de La cámara lúcida, con el que lo compara. Por otro lado, Foster piensa en el trauma como repetición: se intenta simbolizar una y otra vez, pero siempre algo queda afuera, por eso se insiste. En efecto, Warhol no produce una imagen sino una serie, con pequeñas diferencias: una mancha, por ejemplo, que parece una lágrima en el accidente de ambulancia. Y es allí donde, para Foster, emana algo del orden de lo real.

Las ideas de Foster están en el origen del trabajo de compilación realizado por Jens Andermann y Álvaro Fernández Bravo en La escena y la pantalla, un conjunto de artículos destinados a reflexionar en torno al retorno de lo real en el cine contemporáneo, en especial en el llamado $\mathcal{N u e v o}$ Cine Argentino en nuestro país y, en Brasil, el cinema da retomada. Diversos filmes producidos en ese contexto presentan, según Fernández Bravo y Andermann, "un real traumático que remitiría a vivencias resistentes a ser reinscriptas en tramas coherentes sin dejar resto" (8). En ellos, "la distancia entre apariencia (film) y realidad (hecho) se disuelve hasta desaparecer" (13), en la medida en que "acontecimiento, trauma, filmación e intervención de los medios resultan yuxtapuestos sobre una misma superficie" (13).

Los rubios, en ese sentido, constituye un ejemplo paradigmático. Sin embargo, todas estas producciones, ya sea desde procedimientos fílmicos o narrativos, de alguna manera encarnan esta tensión entre una fuerza que insiste en la búsqueda y otra que dispersa. El resultado es una suerte de falla, algo que en el tironeo se rasga y queda descubierto. Es allí que irrumpe lo real: eso que nunca se va a saber del todo, y por lo tanto nunca podrá decirse del todo. En Bruzzone, por ejemplo, se pierde o se supera la posibilidad de una clara visión sobre los hechos del pasado: hay algo que permanece vacío, un núcleo que se rodea, pero no se toca. En el mismo sentido, puede leerse la imposibilidad de conseguir información que desespera a Nicolás Prividera en $M$, en cuyo reverso se encuentran el tesón y la insistencia de la investigación. 
En especial, en $M$, el hueco surge en relación con la militancia de la madre. A lo largo de la película, Nicolás intentará obtener información sobre el tema: ¿por qué la secuestraron? ¿en qué "andaba"? ¿"andaba" en algo? ¿tomó las armas? ¿puso en riesgo a sus hijos? Los entrevistados evaden casi siempre estas preguntas, dicen no saber o no recordar, y cuando responden son confusos, vagos, se contradicen. La cuestión atañe a una tensión crucial de casi todos los relatos de los HIJOS: aquella que se da entre la dimensión social y la individual de la historia que se busca reconstruir y contar. Nicolás Prividera, plenamente consciente de esta tensión, insiste en varios momentos de la película en el carácter colectivo, social, del trauma. Por ejemplo, cuando alguien le pregunta si lo enoja lo que pasó, él responde que sí, como a todos, "no es algo que me hicieron". En Papá Iván, la misma frontera se reescribe en términos de lo público y lo privado, o lo doméstico, en el marco de la confrontación de los testimonios de los compañeros de militancia del padre con el testimonio de la madre de María Inés Roqué, quien cuenta cómo se separaron cuando él pasó a la clandestinidad y ella no, y habla de razones políticas pero también de que él se fue con otra mujer. Dice Ana Amado:

El relato de la madre, en cambio, intercala inesperadas tramas de afecto, introduce desvíos minimalistas en el cerrado logos masculino sobre la violencia histórica [...] la madre repone el paisaje interior -en el sentido doble de la interioridad, la doméstica y la individual- de aparente intrascendencia frente a la historia espectacularizada en la versión paterna $[\ldots]$ es la voz de la madre, finalmente, la que liga los fragmentos biográficos en un montaje narrativo que expone la relación entre cuerpo, ideología, poder y género femenino, como quien anuda las potencialidades discordantes de lo político y lo histórico con las Vidas privadas. (Amado 179)

En efecto, la pregunta por cómo lograron los padres conciliar la vida familiar con la militancia política, si es que lo hicieron, y el intento, siempre fallido, de suturar ellos mismos esas dos dimensiones, aparece de una manera u otra en todas las producciones de los HIJOS, y dibuja una línea inestable entre dos relatos y, más aún, entre dos tipos de relatos. Respecto de Historias cotidianas, de Andrés Habegger, Ana Amado afirma: "no erige en ese lugar una imagen paterna nueva ni 'buena', sino una idea indecidible entre el perfil épico del protagonista de una gesta histórica colectiva y el de un desertor radical del mundo de los afectos privados" (184). 
Hay, entonces un universo doméstico o familiar y un universo exterior o extraño que ni los chicos de entonces ni los adultos de ahora consiguen deslindar -tal es la condición de indecidibilidad que señala Amado-. Y es justo allí, en esa superposición de lo familiar y lo extraño, que aparece lo siniestro, tal como fuera definido por Freud y que, recordemos, era una de las formas de lo real: un efecto, sin dudas traumático, que se produce ante el reconocimiento de un rasgo familiar en lo extraño; el instante de comprensión de que lo que parece extraño era antes familiar y se ha vuelto extraño en el proceso de su represión.

En ese sentido, cabe destacar que el efecto de lo siniestro se produce en una zona de contigüidad pero también de falla, de desacomodo, entre lo familiar y lo extraño, en sus muy diversas manifestaciones: lo doméstico y lo político pero también lo propio y lo ajeno, lo biográfico-testimonial y lo literario, la primera y la tercera persona e, incluso, lo superficial y lo crítico, en el sentido en que lo planteaba Foster en su lectura de Warhol y en el sentido en que aparece, también, en los debates que ha suscitado entre la crítica la película Los rubios.

\section{V}

En un artículo publicado en Punto de vista, Martín Kohan argumentó a favor de la idea de que Los rubios constituye una celebración de la apariencia. Para Kohan, hay que pensar la película no como un intento de aproximarse al pasado -en tanto tal, fracasa- sino, al contrario, como un intento de poner distancia, de alejar. Los testimonios de la militancia, entonces, son incluidos "pero tan solo para que veamos de qué manera se los aparta" (28): de allí resulta una postergación de la dimensión más específicamente política en el filme. Si "toda representación del pasado histórico lucha contra sus propias imposibilidades", Albertina Carri sin embargo "se da por vencida con sospechosa prontitud" (28). Por ejemplo, al representar el secuestro de los padres con muñecos playmobil animados, el efecto es el de la supresión "de una realidad, la de la violencia política", rayana en la frivolidad. La escena final en que Carri y su equipo de filmación se alejan caminando con pelucas rubias es interpretada en esta línea por Kohan, quien ve allí un claro ejemplo de celebración de las apariencias. ${ }^{7}$

7 El artículo de Kohan fue el puntapié inicial de un fecundo debate, a partir de que Cecilia Macón escribiera una respuesta en el número siguiente de Punto de vista. En sus propios análisis de la película, tanto Gonzalo Aguilar (2010) como Ana Amado (2009) intervienen, 
Detengámonos por un instante en la escena final de Los rubios y en la centralidad que tiene en el filme, desde el título, la cuestión del color de pelo: los vecinos del barrio del conurbano en el que los Carri vivieron los últimos meses los recuerdan como rubios, a pesar de que Albertina remarca una y otra vez que no lo eran. Esa suerte de duplicación se suma a otras, sobre las cuales Los rubios se sostiene: la fundamental es la presencia de una actriz (Analía Couceyro), que hace de Carri, aunque Carri permanece también frente a cámara. Pero ya antes, en la primera escena, una antigua vecina de la familia que es entrevistada oscila entre dirigirse a Carri en segunda persona -una de las primeras cosas que dice es: ahora sí te reconozco- y hablar de Albertina como si no estuviera presente. La película se mueve así en ese borde entre el reconocimiento y el desconocimiento, entre la identificación y la extrañeza, entre la primera y la tercera persona; en esa "contigüidad y confusión de la ficción y lo testimonial" (Aguilar 180).

Pero, por otro lado, allí ocurre algo: casi sin darse cuenta -o aparentándolo- una vecina revela que fue ella quien delató a los padres de Carri. Cuando los militares entraron por error a su casa ella habló de "los rubios" y los militares entendieron la referencia a pesar del equívoco y así fue como los encontraron y se los llevaron: "En la falsa identificación de estas vecinas (nada reticentes, por cierto) late entonces una verdad: la más profunda verdad de esta historia, la que costó el secuestro y la desaparición de Roberto Carri y Ana María Caruso" (Kohan 3o).

Según Alan Pauls, "lo verdaderamente siniestro de la época de la dictadura" fue aquello que, como el Mundial 78 o la Guerra de Malvinas, exigió de la población algo más que los cuerpos:

Las fuerzas armadas, los torturadores y los programas del gran capital siempre nos han aliviado porque nos condenan al papel de inocentes, víctimas indefensas, meros objetos o soportes de una violencia que se nos impone desde el exterior. El Mundial '78 y Malvinas, en cambio, nos implican -en el sentido más criminal de la palabra- porque sólo podían funcionar si sintonizaban con lo que era, al parecer, el núcleo mismo de nuestra humanidad: nuestra fe, nuestra ilusión, nuestro deseo.

aunque más indirectamente, al afirmar que Los rubios es, a diferencia de lo que sostiene Kohan, una película eminentemente política. 
En ese sentido, lo que aparece en la escena de la delación de Los rubios, es la complicidad civil: una verdad que pertenece al orden de lo siniestro. En Los rubios, lo siniestro hace su aparición por medio de la figura del doble -de la duplicación-, que es, de hecho, una de las formas principales en que se manifiesta, ya para Freud, la tensión entre lo familiar y lo extraño que define lo siniestro. Pero el efecto de duplicación tiene un límite, o más bien, se produce en un límite, que Los rubios explora y problematiza: cuando Carri tiene que ir a sacarse sangre para dejar una muestra en el banco de datos genéticos, va Couceyro. Pero después tiene que ir, necesariamente, Carri. La escena, pues, se produce dos veces.

Otra suerte de duplicación, igualmente siniestra, aparece en el ámbito literario en el Diario de una princesa montonera. Se trata de una "filiación paradojal": la del encuentro con quien fuera el novio de su madre antes de su padre, Martín, quien aparentemente nunca pudo olvidar aquel amor. Mariana Eva y Martín inician una relación de amistad que desde el comienzo es caracterizada como extraña, pero que termina de complejizarse -y se termina, de hecho- durante un viaje que ella realiza a Francia, invitada por él. Justo antes Mariana Eva Pérez había contado cuáles eran sus fantasías: que, al casarse, sea Martín quien "la entregue": es decir, que actúe como un padre. Si el Diario está compuesto por distintos tipos de textos -diálogos, sueños, entradas de blog-e incluso imágenes, el relato de lo que pasó entonces es una de las pocas partes escritas en forma de poema, una forma, podríamos decir, eminentemente literaria -sobre lo cual la autora no deja de ironizar-:

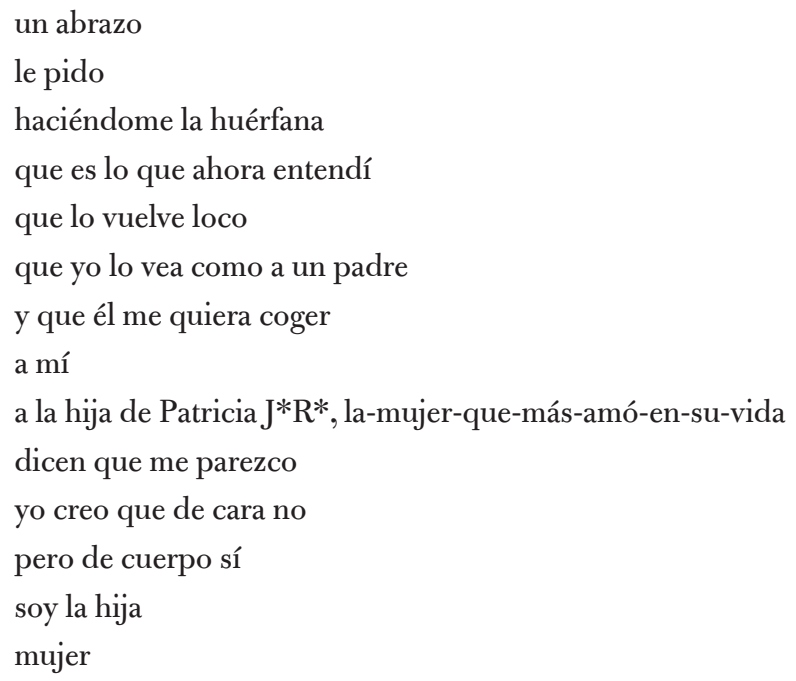


de la mujer con la que fantaseó minuciosamente cada noche en prisión la hija que tuvo con OTRO

$[\ldots]$

te pedí un abrazo

mi abrazo

debe ser como el de Paty

ella era más alta

pero vos también eras más alto entonces

en el abrazo debo ser igual

el mismo cuerpo

sin cara

(Pérez 180-182)

En otras partes del Diario, la duplicación tiene una impronta teatral: la primera persona del diario deja lugar a una tercera, en la introducción de diálogos en los que María Eva Pérez participa como personaje, "vista desde afuera". Las escenas dialogadas corresponden, casi siempre, a momentos difíciles de encuentro con el pasado traumático, como los juicios o una visita a la ESMA; en ellas, no hay lugar para el humor, a diferencia del resto del libro. En ese sentido, puede leerse esta oscilación entre la primera y la tercera persona -que también aparece, recordemos, en el final de Campo de Mayo- en relación con la lectura que hiciera Ricardo Piglia de los textos en que Rodolfo Walsh relata su propio horror -la muerte de su hija Vicki- dejando la palabra, en un momento clave, a una tercera persona, un hombre en el tren o un soldado:

Me parece que ese movimiento, ese desplazamiento, darle la palabra al otro que habla de su dolor, un desconocido en un tren, un desconocido que está ahí, que dice "Sufro, quisiera despertarme dentro de un año", ese desplazamiento, casi una elipsis, una pequeña toma de distancia respecto a lo que está tratando de decir, es una metáfora del modo en que se muestra y se hace ver la experiencia del límite, alguien habla por él y expresa el dolor de un modo sobrio y directo y muy conmovedor.

Walsh realiza entonces un pequeñísimo movimiento para lograr que alguien por él pueda decir lo que él quiere decir. Un desplazamiento, y ahí está todo -el dolor, la compasión-: una lección de estilo. Un movimiento pronominal, casi una forma narrativa de la hipálage, un intercambio que me parece muy importante para entender cómo se puede llegar a contar ese punto ciego de la experiencia, mostrar lo que no se puede decir. 


\section{$[\ldots]$}

Quizá ese soldado nunca existió, como quizá nunca existió ese hombre en el tren: no es eso lo que importa, sino la visión que se produce. Lo que importa es que están ahí para poder narrar la experiencia. Puede entenderse como una ficción, tiene por supuesto la forma de una ficción destinada a decir la verdad. El relato se desplaza hacia una situación concreta donde hay otro, inolvidable, que permite fijar y hacer visible lo que se quiere decir. (Piglia)

Ya Agamben había señalado lo vicario como una cualidad central del testimonio, en su lectura de los testimonios de los sobrevivientes de los campos de concentración nazis, como Primo Levi. En efecto, en Lo que queda de Auschwitz, afirma que solo quien tuvo la experiencia total del campo es quien podría testimoniarla, pero es quien ha muerto: la muerte es la experiencia total del campo. Por eso, quienes sí pueden dar testimonio lo hacen siempre en lugar de otros y sus testimonios tienen siempre lo que él llama una laguna. Esta idea es extensible a otros testimonios del horror, como los del caso argentino. Y, eventualmente, a todo testimonio. Blanchot y Derrida (2000) van un poco más allá al afirmar que, en la medida en que solo el testigo estuvo ahí, el testimonio entraña siempre la posibilidad de perjurio, de mentira, de ficción: es decir, la posibilidad de la literatura. ${ }^{8}$ Desde otra perspectiva, en la interpretación de Piglia se llega a una conclusión similar: ceder la palabra a otro permite decir lo indecible, pero al mismo tiempo supone un movimiento hacia la ficción, hacia la literatura, que es lo que Bruzzone en efecto representa en Campo de Mayo, donde el pasaje a la tercera persona se produce en el marco de la escritura de una novela y de la conversión del propio Bruzzone en escritor. En el caso de las producciones de hijos de desaparecidos, esta tensión se pronuncia en la medida en que su lugar es a la vez intermedio, como venimos diciendo: partícipes y testigos de una historia propia y ajena, individual y colectiva, son ellos mismos la primera y la tercera per-

8 "If the testimonial is by law irreducible to the fictional, there is no testimony that does not structurally imply in itself the possibility of fiction, simulacra, dissimulation, lie and perjury -that is to say, the possibility of literature, of the innocent or perverse literature that innocently plays at perverting all of these distinctions. If this possibility that it seems to prohibit were effectively excluded, if testimony thereby becomes e proof, information, certainty, or archive, it would lose its function as testimony. In order to remain testimony, it must therefore allow itself to be haunted. It must allow itself to be parasitized by precisely what it excludes from its inner depths, the possibility, at least, of literature" (Blanchot y Derrida 29-30). 
sona: sus búsquedas de la verdad y sus testimonios rodean un vacío, una laguna, un real que siempre deja resto y en ese movimiento no pueden sino desplazarse hacia lo literario.

Otro límite central en el que se juegan estos filmes es el que separa la infancia -el momento en que ocurrió la desaparición de los padres, ese instante traumático al que se vuelve una y otra vez- de la adultez, punto de partida del recuerdo. Claro que ambos momentos son más bien contiguos en estas producciones y se entremezclan de diferentes maneras. Así como en La casa de los conejos la voz narrativa conjuga la mirada de la niña con la reflexión de la adulta, en Los rubios hay, desde la construcción propia del cine diversas instancias en que remiten a lo infantil: hay una escena, en el barrio en el que vivieron y fueron secuestrados los padres de Carri, en que Analía Couceyro/Albertina Carri dialoga con unos chicos que están jugando en la calle y les pregunta por la casa en la que vivió de chica. Enseguida los chicos cuentan que allí vivía un señor que se llamaba Jorge, y que murió. Van saltando de versión en versión: que se mató, que se murió porque no soportaba a la mujer, que estaba mal del hígado. El relato es un juego y resulta imposible saber cuál es la verdad, si recuerdan o inventan: en cualquier caso, hay un núcleo duro del relato que permanece e insiste y tiene que ver con la muerte.

Pero también, en Los rubios, el propio relato está construido con elementos infantiles, como el juego y la risa, que se conjugan con el imperativo adulto de recordar. Según Ana Amado, incluso el intercambio de personalidades entre Carri y Couceyro puede verse como una suerte de juego de chicos, de juego de rol. Y, fundamentalmente, es central en Los rubios la representación de las escenas de infancia en que los padres estaban vivos y, en especial, la de su secuestro, con muñecos playmobil animados. En relación con ello, quisiera proponer una lectura diferente o, más bien, complementaria a la de Kohan: la frivolidad innegable de la escena está lejos de suprimir la realidad de la violencia política. Por el contrario, esta ingresa al filme bajo un modo de lo siniestro que es propio de los muñecos animados, equivalentes en alguna medida a los autómatas a los que refería Freud.

En su exhaustivo análisis de la miniatura, Susan Stewart señala que esta entraña una ambigüedad fundamental. Es siempre un producto cultural, que supone un procedimiento y un punto de vista: la perspectiva trascendente, humana; en ese sentido, "presenta una versión de la experiencia diminuta y por lo tanto manipulable, una versión que está 
domesticada y protegida de contaminación" (Stewart 69; la traducción es mía). Sin embargo, al mismo tiempo que vemos las miniaturas como objetos nos preguntamos si no tendrán una vida secreta, si hay una acción que no vemos, si existe, acaso, una narración que escape a la percepción y por lo tanto al control: estas preguntas que despierta la miniatura se vuelcan, dice Stewart, en las historias de juguetes que cobran vida. Y es que las miniaturas son producidas y existen en el límite entre lo animado y lo inanimado, lo vivo y lo muerto: al mismo tiempo que lo trazan, lo cruzan y lo desdibujan.

Si hubo una formulación siniestra del accionar de la dictadura militar, fue la que pronunció el presidente de facto Jorge Rafael Videla en una conferencia de prensa en 1979: "El desaparecido, en tanto esté como tal, es una incógnita el desaparecido. Si el hombre apareciera, bueno, tendrá un tratamiento X y si la desaparición se convirtiera en certeza de su fallecimiento, tiene un tratamiento $\mathrm{Z}$, pero mientras sea desaparecido no puede tener ningún tratamiento especial, es una incógnita, es un desaparecido, no tiene entidad, no está, ni muerto ni vivo, está desaparecido". La ubicación liminar del desaparecido -ni muerto ni vivo-, de la que deriva toda la serie de imposibilidades, para la sociedad en general y para sus hijos en particular, respecto de su simbolización parece convertirse aquí en su opuesto: no es ya la liminaridad un eufemismo para lo muerto ni la declaración de una imposibilidad sino, por el contrario, una zona en donde se apuesta por la representación, por vía de las operaciones ficcionales, como un modo de cobrar vida, de volverse presente. ${ }^{9}$ En relación con ello, Stewart señala que la miniatura se sitúa en el centro del problema de la representación, en la medida en que aumentar la brecha entre lo material -es decir, el significante, que es reducido-y lo abstracto -es decir, el significado, que se potencia-.

De una manera similar se ocupa y se desestabiliza en muchas de estas obras el límite entre lo humano y lo animal. En la novela de Laura Alcoba, los conejos son la fachada que encubre, pero al mismo tiempo permite decir la actividad ilegal de la madre: "los conejos han llegado en el momento en que la imprenta ha empezado a funcionar regularmente" (74). A partir de entonces, los conejos se amontonan igual que se amontonan las

9 Es en ese sentido, en parte, que puede entenderse la afirmación de Gonzalo Aguilar de que estos filmes restituyen de alguna manera, para los HIJOS, la posibilidad de duelo, que la ausencia de cuerpo dificultó durante muchos años. 
revistas, en el criadero se multiplica el blanco al mismo ritmo en que se multiplica el negro en las manos de la madre. Enseguida, Diana le pide a la pequeña Laura que sostenga a un conejo para que ella le dé el golpe fatal en la nuca y puedan comerlo. La inexperiencia de Diana -el martillo de milanesas resulta insuficiente, entonces recurre a una plancha, mientras el conejo se retuerce sobre la mesa- y la poca fuerza de la niña vuelven la escena mucho más tortuosa, aunque al final el conejo muere. El animal, sobre la mesa, sufriendo un lento y doloroso paso hacia la muerte hace pensar en la tortura. Por otra parte, se destaca el hecho de que para la niña -y para la adulta que narra la escena desde su perspectiva- la escena no reviste carácter traumático: encariñada con Diana, la pequeña Laura lo vive como un juego en el que no hay horror, y es eso precisamente lo que le permite contar la escena, que sí resulta horrorosa para el lector.

En la misma línea, es decir, en relación con la cuestión de cómo decir o, más bien, cómo mostrar la tortura funcionan las vacas en Los rubios. Casi sobre el final, Couceyro/Carri cuenta que fue con su hermana a enmarcar una foto. Y allí, en la casa de marcos, es decir, de casualidad, vieron una foto en un matadero. Su hermana dijo que tenía que haberla sacado alguien a quien hubieran torturado. Semanas después se enteran de que la autora de la foto es la única sobreviviente del centro clandestino de detención donde estuvieron los Carri. La fotógrafa, que se llama Paula, no quiere hablar ante la cámara. No habló en la tortura, dice, por qué va a hablar ahora. Carri entonces se pregunta qué relación hay entre la cámara y la picana, y qué relación hay, para la fotógrafa, entre su propia cámara y el hacha con que matan a la vaca en la foto.

La cuestión de la representación aparece de una forma especialmente explícita: la propia torturada, que no quiere dar testimonio frente a la cámara, saca fotos con su cámara de la matanza de vacas y alguien puede leer allí la tortura. En efecto, los animales, que son aquellos que pueden matarse sin castigo -y ningún ejemplo más cabal de esto que los animales que se matan para comer, como las vacas en el matadero o el conejo en la cocina de la casa- aparecen entonces como una vía de representación de lo irrepresentable: los humanos que también pudieron matarse sin castigo -y que se mataron, además, con métodos cruentos, inhumanos, por fuera de la ley-. ${ }^{10}$

10 En este sentido, puede postularse como un antecedente de este uso de la animalidad como modo de narrar el horror de la desaparición la novela Nadie nada nunca, de Juan José Saer. 
Sin embargo, como señala Gabriel Giorgi, esa representación no funciona como un símbolo, no hay alegoría: en gran parte de la literatura contemporánea, lo animal ha dejado de ser otro absoluto de lo humano para convertirse en "una vida animal sin forma precisa, contagiosa, que ya no se deja someter a las prescripciones de la metáfora y, en general, del lenguaje figurativo, sino que empieza a funcionar en un continuum orgánico, afectivo, material y político con lo humano" (Giorgi 12). La relación de lo humano y lo animal pasa a ser, ahora, la de la metonimia: la de la contigüidad.

\section{VI}

Así, hemos recorrido algunas de las formas en que las producciones, tanto literarias como fílmicas, realizadas por hijos de desaparecidos durante los últimos años, presentan un tipo de articulación entre los elementos biográficos y los procedimientos ficcionales, que coincide con lo que la crítica cultural ha denominado giro documental. Principalmente, los datos de la realidad se inscriben en la ficción metonímicamente más que reflejarse en ella por medio de metáforas. En ese sentido, constatamos que estas producciones se desarrollan en una zona de contigüidad entre lo testimonial y lo ficcional en la que tienen lugar diversas oscilaciones: entre la primera y la tercera persona, lo individual y lo colectivo, lo familiar y lo extraño, lo animado y lo inanimado, lo animal y lo humano. Vimos también que en esa zona liminar se producen una suerte de fallas, por las que se cuela lo real. Las producciones de los HIJOS consiguen, así, decir algo de esa historia -en el doble sentido, de historia personal e historia social- traumática que al mismo tiempo es y no es la suya.

En ese marco, el cine parece constituir un antecedente -y no es casual que las primeras producciones de HIJOS aparezcan en ese ámbito- para la literatura, en relación con ese modo peculiar de inscripción de lo real como índice que caracteriza a la imagen fílmica y que las películas de los HIJOS, en el marco del surgimiento del Nuevo Cine Argentino, convocan y desarrollan. 


\section{Obras citadas}

Aguilar, Gonzalo. Otros mundos. Un ensayo sobre el nuevo cine

argentino. Buenos Aires: Santiago Arcos, 2010. Impreso.

Alcoba, Laura. La casa de los conejos. Buenos Aires: Edhasa, 2008. Impreso.

Amado, Ana. La imagen justa. Buenos Aires: Colihue, 2009. Impreso.

Andermann, Jens y Álvaro Fernández Bravo. La escen a y la pantalla. Cine contemporáneo y el retorno de lo real. Buenos Aires: Colihue, 2013. Impreso.

Blanchot, Maurice y Jacques Derrida. The instant of my death/Demeure, fiction and testimony. Stanford: Stanford University Press, 2000. Impreso.

Borges, Jorge Luis. "La muralla y los libros". La nación (22 de octubre de 1950). http://www.lanacion.com.ar/814407-la-muralla-y-los-libros. Web.

Bruzzone, Félix. 76. Buenos Aires: Tamarisco, 2008. Impreso.

Bruzzone, Félix. Los topos. Buenos Aires: Mondadori, 2008. Impreso.

Carri, Albertina y María Moreno. "Esa rubia debilidad". Radar (19 de octubre de 2003). https://www.pagina12.com.ar/diario/suplementos/radar/9-1001-2003-10-22.html. Web.

Contreras, Sandra, comp. Realismos. Cuestiones críticas. Cuadernos del seminario II. Rosario: UNR, 2013. Impreso.

Freud, Sigmund. Lo siniestro. Buenos Aires: Ediciones Noé, 1973. Impreso.

Gamerro, Carlos. "Tierra de la memoria". Radar (11 de abril de 2010). http://www. pagina12.com.ar/diario/suplementos/libros/10-3787-2010-04-11.html. Web.

Gelman, Juan y Mara la Madrid. Ni el flaco perdón de dios. Buenos Aires: Planeta, 2017. Impreso.

Giorgi, Gabriel. Formas comunes. Buenos Aires: Eterna Cadencia, 2014. Impreso.

Kamenszain, Tamara. Una intimidad inofensiva. Los que escriben con lo que hay. Buenos Aires: Eterna Cadencia, 2016. Impreso.

Kohan, Martín. "La apariencia celebrada". Punto de vista 78 (Buenos Aires, abril de 2004): 24-30. Impreso.

Pauls, Alan. "Malvinas' 78". Radar (1 de junio de 2008). http://www.pagina12.com. ar/diario/suplementos/radar/subnotas/4639-754-2008-06-02.html. Web.

Pérez, Mariana Eva. Diario de una princesa montonera.

Buenos Aires: Capital Intelectual, 2012. Impreso.

Piglia, Ricardo. "Tres propuestas para el próximo milenio". Radar

(23 de diciembre de 2001). http://www.pagina12.com.ar/2001/ suple/Radar/01-12/01-12-23/NOTA2.HTM. Web.

Sarlo, Beatriz. Tiempo pasado. Buenos Aires: Siglo XXI, 2005. Impreso.

Sarlo, Beatriz. "Sujetos y tecnologías. La novela después de la historia".

Punto de vista 86 (Buenos Aires, diciembre de 2006): 1-6. Impreso.

Stewart, Susan. On longing. Londres: Duke University Press, 1993. Impreso. 